\section{(a)} OPEN ACCESS

\title{
Child growth and neurodevelopment after maternal antenatal antibiotic treatment
}

\author{
Karoliina Videman (1) ${ }^{1,2}$ Lotta Hallamaa, ${ }^{1}$ Otto Heimonen, ${ }^{1}$ Charles Mangani, ${ }^{3}$ \\ Mari Luntamo, ${ }^{1}$ Kenneth Maleta, ${ }^{3}$ Per Ashorn, ${ }^{1,2}$ Ulla Ashorn ${ }^{1}$
}

\begin{abstract}
- Additional supplemental material is published online only. To view, please visit the journal online (http://dx.doi. org/10.1136/archdischild2021-322043).
\end{abstract}

${ }^{1}$ Faculty of Medicine and Health Technology, Center for Child, Adolescent and Maternal Health Research, Tampere University, Tampere, Finland ${ }^{2}$ Department of Paediatrics, Tampere University Hospital, Tampere, Finland

${ }^{3}$ Department of Public Health, School of Public Health and Family Medicine, College of Medicine Malawi, Blantyre, Malawi

Correspondence to Dr Karoliina Videman, Tampere University Hospital, Tampere 33520, Finland;

karoliina.videman@tuni.fi

Received 13 March 2021 Accepted 17 August 2021
Check for updates

(C) Author(s) (or their employer(s)) 2021. Re-use permitted under CC BY-NC. No commercial re-use. See rights and permissions. Published by BMJ.

\footnotetext{
To cite: Videman $\mathrm{K}$, Hallamaa L, Heimonen 0 , et al. Arch Dis Child Epub ahead of print: [please include Day Month Year]. doi:10.1136/

archdischild-2021-322043
}

\begin{abstract}
Objective To assess whether intermittent preventive treatment of pregnant women (IPTp) with sulfadoxinepyrimethamine (SP) and azithromycin (AZI) in a malariaendemic area leads to sustained gains in linear growth and development in their offspring.

Design Follow-up study of a randomised trial.

Setting Mangochi District in rural southern Malawi.

Participants 1320 pregnant women and their

offspring.

Interventions IPTp monthly with SP and twice with AZI (AZI-SP group), monthly with SP but no AZI (monthly SP), or twice with SP (control). No intervention was given to children.
\end{abstract}

Main outcome measures Cognitive performance using Raven's Coloured Progressive Matrices (CPM) at 13 years of age; mean height and height-for-age Z-score (HAZ), cumulative incidence and prevalence of stunting (HAZ <-2); weight, body mass index, mid-upper-arm circumference and head circumference.

Results At approximately 13 years of age, the mean CPM score was 14.3 (SD 3.8, range 6-29, maximum 36), with no differences between groups. Children in the AZI-SP group were on average $0.4 \mathrm{~cm}(95 \% \mathrm{Cl}$ -0.9 to $1.7, p=0.6$ ) taller than those in the control group. For cumulative incidence of stunting, the $H R$ in the AZI-SP group was $0.72(95 \% \mathrm{Cl} 0.61$ to 0.84 , $p<0.001)$ compared with the control and $0.76(95 \% \mathrm{Cl}$ 0.65 to $0.90, p<0.001$ ) compared with the monthly SP groups. There was no intergroup difference in stunting prevalence or anthropometric measurements.

Conclusions In rural Malawi, maternal intensified infection control during pregnancy reduces offspring's cumulative incidence of ever being stunted by 13 years of age. In this study, there was no evidence of a positive impact on cognitive performance.

Trial registration number NCT00131235.

\section{INTRODUCTION}

Globally, 21\% of children under 5 years old are estimated to be stunted, most of them living in low-income and middle-income countries. ${ }^{1}$ There is robust evidence that better linear growth during the first 2 years of life is positively associated with cognitive and motor development. ${ }^{2}$ As brain development begins in the third week of gestation and some $75 \%$ of brain growth occurs during the first 1000 days, the antenatal period is crucial for promotion of brain development. ${ }^{45}$

Stunting often has its origins in the fetal period, resulting in fetal growth restriction (FGR) and subsequent growth faltering in the first 2 years of

\section{What is already known on this topic?}

- Stunting is affecting approximately 144 million children under 5 years and is associated with poor child development. Linear growth failure starts during the fetal period.

- Maternal infection control with repeated doses of sulfadoxine-pyrimethamine and azithromycin during pregnancy has been shown to promote fetal growth in rural Malawi.

- This intervention leads to reduced incidence of childhood stunting and better cognitive performance among 5-year-old children.

\section{What this study adds?}

- Maternal preventive infection treatment during pregnancy has no impact on rural Malawian children's postnatal growth or prevalence of stunting after 5 years of age in rural Malawi.

- There is, however, a fetal growth benefit that is sustained after birth and translates to a lower cumulative incidence of ever being stunted in childhood.

- There is no evidence of a sustained effect on cognitive performance.

life. ${ }^{6}$ Nutritional interventions during pregnancy seem to modestly increase mean birth length and weight but these gains are typically lost in infancy. ${ }^{7-9}$ Intermittent preventive treatment of pregnant women (IPTp) with monthly sulfadoxinepyrimethamine (SP) compared with SP twice during pregnancy increases birth weight, but birth length data have rarely been reported. ${ }^{10}$ There is evidence that adding maternal azithromycin (AZI) treatment during pregnancy reduces the prevalence of preterm birth and fetal and neonatal growth faltering in malaria-endemic areas. ${ }^{11} 12$ The impact of these interventions on child development remains unclear. ${ }^{13}$

In a trial in Malawi, we showed that intensified antenatal infection control can reduce stunting in infancy and early childhood and improve cognitive development by 5 years of age. The intervention may also have reduced postneonatal mortality. ${ }^{14} 15$ We now describe the follow-up results from this trial, aimed to assess the sustainability of the gains in cognitive capacity and growth by early adolescence. As later childhood developmental status is known to be affected by not only genetics and 
the first 1000 days period, but also childhood exposures, we wanted to assess any possible differences at approximately 13 years of age. ${ }^{16}$ The main question was if children of mothers who received intensified infection control during pregnancy would (1) still have better cognitive performance, (2) have a lower cumulative incidence of stunting and (3) be taller in preadolescence than children whose mothers received standard care.

\section{METHODS}

Background

The study was a 13-year follow-up to the Lungwena Antenatal Intervention Study (LAIS), a randomised, partially placebocontrolled, outcome assessor-blinded, three-arm clinical trial from rural southern Malawi. ${ }^{17}$ The original trial showed that preterm delivery and low birth weight were lower and infant size at 1 month was bigger with intensive infection treatment during pregnancy. ${ }^{11} 17$ A follow-up at 5 years indicated that the intervention also reduced the incidence of stunting and had a positive effect on child development. ${ }^{14} 15$

\section{Participants and follow-up}

The LAIS enrolled women with uncomplicated second trimester pregnancies at 14-26 weeks gestation by ultrasound assessment who felt fetal movements. Exclusion criteria included severe illness, receipt of AZI during the current pregnancy or SP within the preceding 28 days, allergy to study drugs, and any previous serious allergic reaction.

Participants in the control group received standard Malawian antenatal care, which at the time of the study included IPTp with SP (1500 mg of sulfadoxine and $75 \mathrm{mg}$ of pyrimethamine) twice: at enrolment and between 28 and 34 weeks of gestation. They also received a placebo to AZI. Participants in the monthly SP intervention group received SP monthly from enrolment until 37 gestational weeks and a placebo to AZI as the control group. Participants in the AZI-SP intervention group received monthly SP and active AZI (1000 mg) at enrolment and between 28 and 34 weeks of gestation. No intervention was given to the offspring. Additional detailed methods are provided in the online supplemental information.

The current follow-up was planned as a separate entity and implemented between December 2017 and March 2019. The study team made visits to the homes of children who had participated in the original LAIS trial and were not known to have died. If the participants had moved, the study team attempted to find information on their new location from nearby households. Each participant and at least one of caregiver provided a new informed consent before participation.

We included all children in the analyses except for those with missing data for the specific outcome. Originally, we planned to evaluate the participants at prepubertal phase at approximately 12 years of age. However, due to delays in implementation, the data were collected later than planned, which resulted in a higher mean age and a larger age range. We accounted for age variation by adjusting the analyses for age and pubertal stage.

\section{Outcomes}

Child development was assessed by the Raven's Coloured Progressive Matrices (CPM), which measures non-verbal intelligence and can be used among illiterate people. ${ }^{18} 19$ The reliability and criterion validity have been found good in Africa. ${ }^{20} 21$ The test comprises 36 items; each correct answer provides a score of 1 and each incorrect or no answer is counted as 0 . Two research assistants administered the Raven's test at the study clinic.
Child anthropometry was assessed by two anthropometrists, in triplicate. For the analysis, we used the mean of the first two readings if they did not differ by more than $0.1 \mathrm{~kg}$ for weight or $0.5 \mathrm{~cm}$ for other measurements. If the tolerance limit was exceeded, we calculated the mean from the pair of two measurements closest to each other.

Primary follow-up outcomes were CPM score, child height, weight, body mass index (BMI), mid-upper-arm circumference (MUAC) and head circumference (HC) at approximately 13 years of age. For attained length and acute nutritional status, we also calculated the prevalence of stunting and severe stunting $(<-2$ and $<-3$ height-for-age Z-scores, HAZ) and low and very low BMI (<-2 SD and $<-3$ BMI Z-scores, BMIZ). These dichotomous outcomes were based on age-standardised and sexstandardised HAZ and BMIZ, using the WHO 2007 child growth standard (age $\geq 61$ months). ${ }^{22}$ For the change in Z-scores, we used HAZ and BMIZ values at 5 years, calculated based on the WHO multicentre growth standard for $<61$ months old. ${ }^{23}$ The growth measurements were adjusted for socioeconomic status (SES) and pubertal stage, assessed by a study nurse using Tanner classification. ${ }^{24-26}$ For MUAC and HC, we used absolute values.

\section{Statistical analysis}

A sample size of 440 pregnant women per group was planned to give $80 \%$ power at a $5 \%$ level of significance to detect a $40 \%$ reduction in the rate of preterm delivery, which was the trial's main hypothesis. ${ }^{17}$ Intention-to-treat analyses were used.

For CPM score, absolute height, weight, BMI, MUAC and $\mathrm{HC}$, we calculated the means and the difference between the three groups was tested with least square regression. For prevalence of stunting, severe stunting, low BMI and very low BMI, we calculated percentages and used a log-binomial regression model to estimate risk ratios. To prevent inflated type I errors due to testing between multiple groups, we began hypothesis testing with a global null hypothesis of no difference between any groups using Wald's test. ${ }^{26}$ Null hypotheses were rejected if $\mathrm{p}<0.05$. Pairwise null hypotheses were rejected only if the global null hypothesis was also rejected. We included age, sex, pubertal stage and SES as covariates in the statistical analyses. SES was expressed as a score that was established with principal component analysis by combining information on the building material of the house, main source of water, type of sanitary facility available and ownership of household items.

\section{RESULTS}

Of the 3358 approached pregnant women, 1320 (39.3\%) were enrolled and randomly assigned to the control (436), monthly SP (441) and AZI-SP (443) groups. In the current analysis, we had data for $997(75.1 \%)$ children on development and for 1002 $(75.5 \%)$ on anthropometrics. Success of follow-up was similar between the groups (figure 1).

At enrolment, the intervention groups were similar except for small differences in maternal malaria prevalence and number of previous pregnancies. Mothers who were lost to follow-up were similar to those who stayed in the study except for HIV prevalence $(11 \%$ vs $22 \%, \mathrm{p}<0.001)$ (online supplemental table 1). Pubertal status and years of schooling of the offspring at follow-up were similar between the groups (table 1).

At the follow-up visit, the mean age of the participants was 12.8 (SD 0.9, range 10.9-14.6) years. Their CPM scores ranged between 6 and 29 (online supplemental figure 1). There were no statistically significant differences between the groups (table 2). 


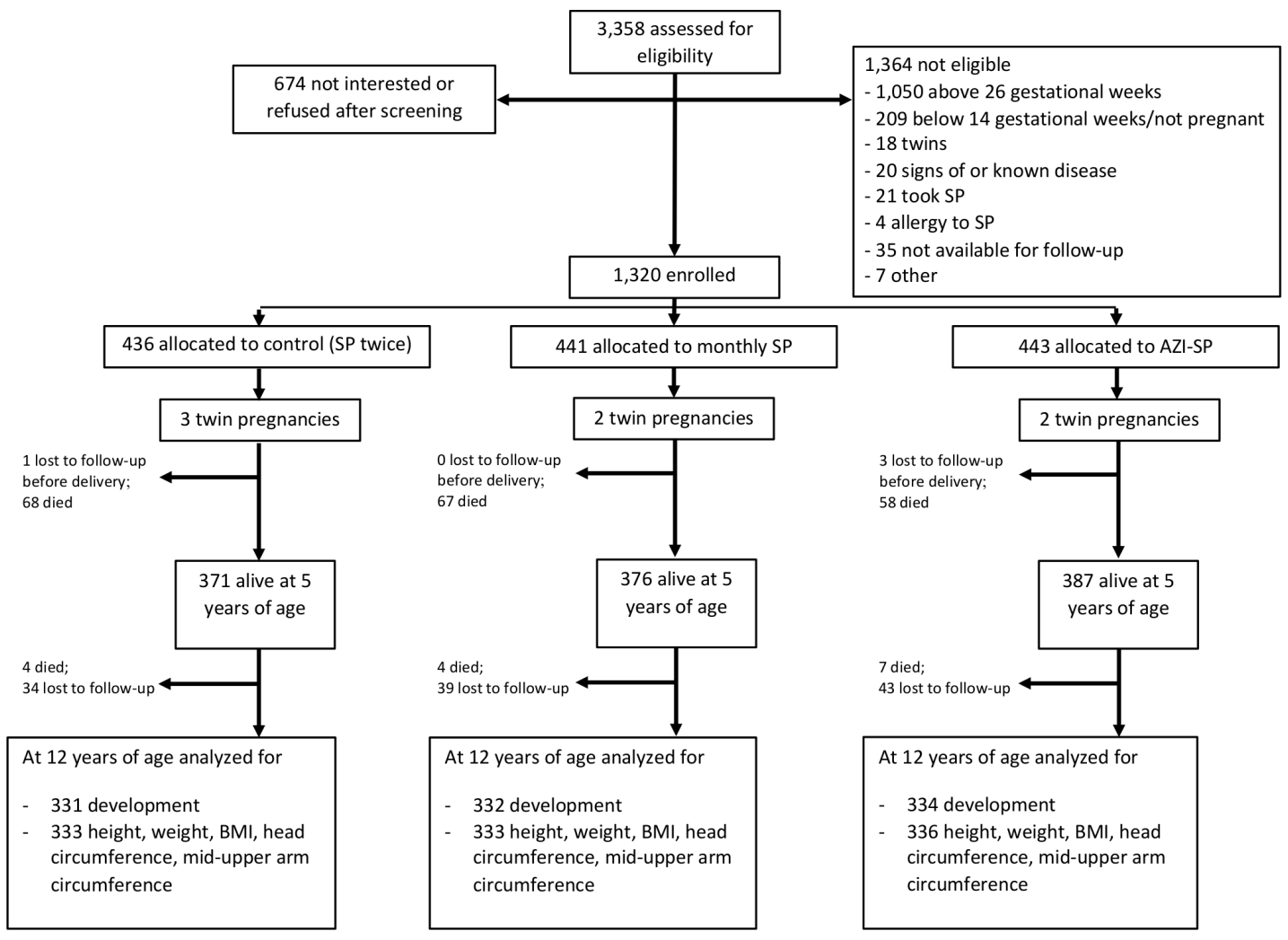

Figure 1 Follow-up of live-born children. Figure created by the authors. AZI-SP, intervention group with monthly SP and two doses of azithromycin; BMI, body mass index; SP, sulfadoxine-pyrimethamine.

The participants' mean height (HAZ) was $52 \mathrm{~cm}(-1.3)$ at 1 month, $81 \mathrm{~cm}(-2.1)$ at 2 years, $102 \mathrm{~cm}(-1.7)$ at 5 years and $143 \mathrm{~cm}(-1.7)$ at 12.8 years (online supplemental figure 2$)$. At the last follow-up, children in the AZI-SP group were on average $0.4 \mathrm{~cm}(95 \% \mathrm{CI}-0.9$ to 1.7$)$ taller than children in the control group (table 2). In absolute length, the point estimate for the intergroup difference was similar to the difference observed at earlier time points, but was statistically significant only at 24 months old or younger (figure 2).

The cumulative incidence of ever being stunted was 79\%, $77 \%$ and $67 \%$ in the control, SP and AZI-SP groups and for severe stunting 42\%, 39\% and 29\%, respectively. The HR $(95 \% \mathrm{CI})$ for being stunted at least once was 0.72 (0.61 to 0.84 , $\mathrm{p}<0.001)$ in the AZI-SP group compared with the control group

Table 1 Baseline characteristics of the participating women at enrolment and their offspring at 13 years, by study group

\begin{tabular}{|c|c|c|c|}
\hline Maternal characteristics & Control (SP twice) $(n=436)$ & Monthly SP $(n=441)$ & AZI-SP $(n=443)$ \\
\hline Age, years, mean (SD) & $25(7)$ & $25(7)$ & $25(6)$ \\
\hline Gestational age at enrolment, weeks, mean (SD) & $20.3(3.0)$ & $20.0(3.2)$ & $20.0(3.0)$ \\
\hline Primiparous (\%) & $110(25.2)$ & $107(24.3)$ & $89(20.1)$ \\
\hline HIV-positive (\%) & $48 / 396(12.1)$ & $64 / 400(16.0)$ & $49 / 398(12.3)$ \\
\hline Microscopic peripheral blood malaria parasitaemia (\%) & $49 / 435(11.3)$ & $41(9.3)$ & $27(6.1)$ \\
\hline Blood $\mathrm{Hb}$ concentration, g/L, mean (SD) & $110(19)$ & $111(17)$ & $110(20)$ \\
\hline Moderate or severe anaemia, $\mathrm{Hb}<100 \mathrm{~g} / \mathrm{L}(\%)$ & $116(26.6)$ & $106(24.0)$ & $129(29.1)$ \\
\hline Literate participants (\%) & $116(26.6)$ & $129(29.3)$ & $139(31.4)$ \\
\hline Years of schooling completed, mean (SD) & $2.1(2.7)^{*}$ & $2.2(2.6)$ & $2.4(2.8)$ \\
\hline Offspring characteristics at 13 years of age & $\mathrm{n}=333$ & $\mathrm{n}=333$ & $\mathrm{n}=337$ \\
\hline \multicolumn{4}{|l|}{ Years of schooling completed } \\
\hline $0(\%)$ & $48(14.4)$ & $62(18.6)$ & $53(15.7)$ \\
\hline $1-3(\%)$ & $186(55.9)$ & $168(50.5)$ & $163(48.4)$ \\
\hline$>3(\%)$ & $99(29.7)$ & $103(31.0)$ & $121(36.0)$ \\
\hline Pubertal stage & $n=332$ & $n=330$ & $n=333$ \\
\hline Stage $1(\%)$ & $162(48.8)$ & $175(53.0)$ & $155(46.6)$ \\
\hline Stage $2(\%)$ & $100(30.3)$ & $88(26.7)$ & $101(30.1)$ \\
\hline Stages 3-5 (\%) & 70 (21.1) & $67(20.3)$ & $77(23.1)$ \\
\hline
\end{tabular}

*Value missing for one participant.

AZI-SP, intervention group with monthly SP and two doses of azithromycin; Hb, haemoglobin; SP, sulfadoxine-pyrimethamine. 
Table 2 Mean developmental outcome, height, weight, BMI, MUAC and HC in preadolescence, by intervention group

\begin{tabular}{|c|c|c|c|c|c|}
\hline Outcome & $\begin{array}{l}\text { Control (SP twice) }(n=333) \\
\text { Mean (SD) }\end{array}$ & $\begin{array}{l}\text { Monthly SP }(n=333) \\
\text { Mean (SD) }\end{array}$ & $\begin{array}{l}\text { AZI-SP }(n=336) \\
\text { Mean (SD) }\end{array}$ & Global $p$ value & $\begin{array}{l}\text { Global } p \text { value, } \\
\text { adjusted* }\end{array}$ \\
\hline Raven's score $†$ & $14.2(3.7)$ & $14.4(3.8)$ & $14.2(3.9)$ & 0.8 & 0.8 \\
\hline Height (cm) & $142.7(8.1)$ & $142.5(8.2)$ & $143.1(8.4)$ & 0.6 & 0.7 \\
\hline Weight $(\mathrm{kg})$ & $33.8(6.3)$ & $33.8(6.9)$ & $34.2(6.5)$ & 0.6 & $>0.9$ \\
\hline BMI & $16.4(1.7)$ & $16.5(2.1)$ & $16.5(1.6)$ & 0.7 & 0.9 \\
\hline MUAC $(\mathrm{cm})$ & $19.9(2.1)$ & $19.8(2.3)$ & $20.0(2.0)$ & 0.2 & 0.5 \\
\hline $\mathrm{HC}(\mathrm{cm})$ & $51.6(1.4)$ & $51.5(1.6)$ & $51.8(1.5)$ & 0.1 & 0.08 \\
\hline
\end{tabular}

${ }^{*}$ Adjusted for child sex, age, socioeconomic status and pubertal stage at the time of developmental assessment and anthropometric measurements.

tFor the Raven's score $n=331, n=332$ and $n=334$.

AZI-SP, intervention group with monthly SP and two doses of azithromycin; BMI, body mass index; HC, head circumference; MUAC, mid-upper-arm circumference; SP, sulfadoxine-pyrimethamine.

and 0.76 (0.65 to $0.90, \mathrm{p}=0.001)$ compared with the monthly SP group. The HR among children in the AZI-SP group for ever developing severe stunting was $0.65(0.51$ to $0.82, \mathrm{p}<0.001)$ and 0.69 (0.54 to $0.88, \mathrm{p}=0.002)$ compared with the control and monthly SP groups, respectively (figure 3 ). The intergroup differences were slightly larger among girls than boys (online supplemental figure 3 ).

At 12.8 years, the mean (SD) weight of the study participants was 33.9 (6.6) kg, BMI $16.5(1.8) \mathrm{kg} / \mathrm{cm}^{2}$, MUAC $19.9(2.1) \mathrm{cm}$ and HC $51.6(1.5) \mathrm{cm}$. There were no significant differences between the groups (table 2). There were also no intergroup differences in most sex-specific analyses (online supplemental tables 2 and 3), except for HC among girls, which were 51.2 $\mathrm{cm}, 51.0 \mathrm{~cm}$ and $51.6 \mathrm{~cm}$ in the control, monthly SP and AZI-SP groups, respectively $(\mathrm{p}=0.006)$.

The prevalence of stunting at 12.8 years was $36 \%, 39 \%$ and $36 \%$ and that of severe stunting $7.5 \%, 8.7 \%$ and $6.0 \%$ in the control, monthly SP and AZI-SP groups, respectively (global $\mathrm{p}$ values 0.6 and 0.4 for stunting and severe stunting). The prevalence of stunting and severe stunting was highest at 24 months, whereas it remained stable from 5 to 12.8 years (online supplemental figure 4). The prevalence of low and very low BMI was $12 \%$ and $1.6 \%$, with no statistically significant differences between the groups $(p=0.2$ for low and $p=0.06$ for very low BMI) (online supplemental table 4).

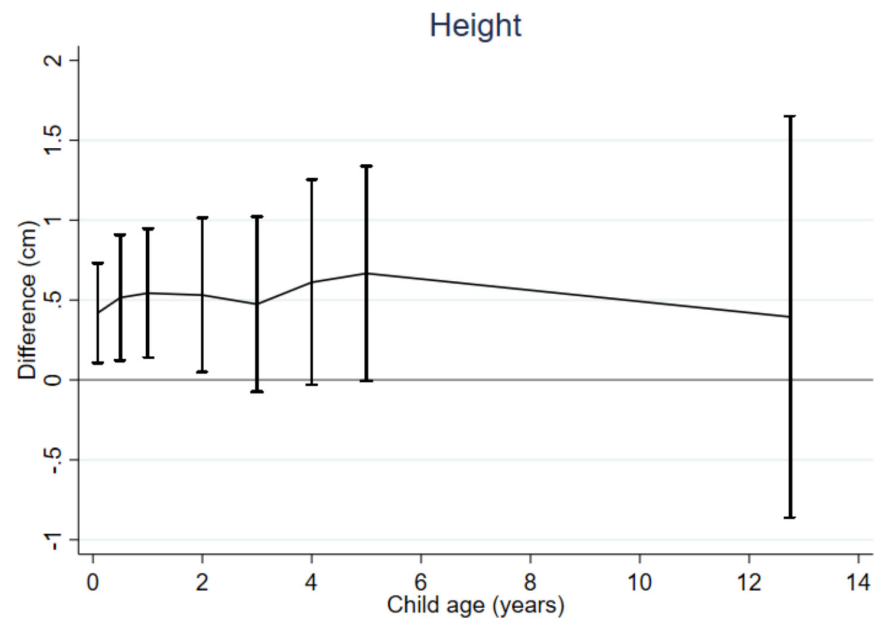

Figure 2 Differences between means in the AZI-SP and control groups and $95 \% \mathrm{Cl}$ in height; measurement points from 1 month to approximately 13 years. Figure created by the authors. AZI-SP, intervention group with monthly sulfadoxine-pyrimethamine and two doses of azithromycin.

\section{DISCUSSION}

Our aim was to test if intensified preventive maternal antenatal infection control would lead to growth and developmental benefits in their offspring still evident in preadolescence. In a sample of 997 Malawian children aged 11-15 years old, there was no difference in mean CPM scores in the different intervention groups. Children whose mothers had received monthly SP and two doses of AZI during pregnancy were on average $4 \mathrm{~mm}$ taller and their cumulative incidence of ever being stunted was $13 \%$ lower than children whose mothers had been treated only with two doses of SP. However, at 11-15 years of age, there was no difference in the prevalence of stunting between the groups.

The validity of our findings could have been compromised by imbalanced group allocation, differential loss to follow-up, missing data, measurement bias and random error in statistical inference. However, the groups were randomly allocated and well balanced at baseline and the proportion of participants lost to follow-up was similar between the groups. The baseline characteristics of those lost to follow-up were similar to those remaining in the study. Maternal HIV infection was associated with loss to follow-up but did not modify the association between the intervention and the studied outcomes (data not shown). The difference in mean height between the groups was not statistically significant in preadolescence, but the point estimate was identical observed when the children were younger. Furthermore, the difference in cumulative stunting incidence was statistically significant. Thus, the sample findings are consistent with a hypothesis that intensified preventive maternal infection treatment during pregnancy leads to a modest impact on the cumulative incidence of stunting, sustained until preadolescence. In contrast, the findings do not support a sustained impact on child development.

Although several earlier trials have studied the impact of maternal antenatal infection control interventions on birth size ${ }^{10-12}$ there are no publications on the impact of these interventions on subsequent child growth. For child development, there are data from the ORACLE trial (antibiotics for preterm, prelabour rupture of membranes and preterm labour) from England, in which women experiencing either preterm premature rupture of membranes (PPROM) or spontaneous preterm labour (SPL) were prescribed either erythromycin, amoxycillinclavulanate, both, or neither. This study suggested a small benefit of erythromycin treatment in newborn survival among women with PPROM. The 7-year follow-up results of the offspring raised concerns about an increased risk of functional impairment in the group that received erythromycin for SPL, and an increased risk for cerebral palsy (CP) with any antibiotic treatment. ${ }^{27} 28$ In a follow-up study carried out at 11 years of age, there was neither harm nor benefit on educational attainment in any group. ${ }^{29}$ The 


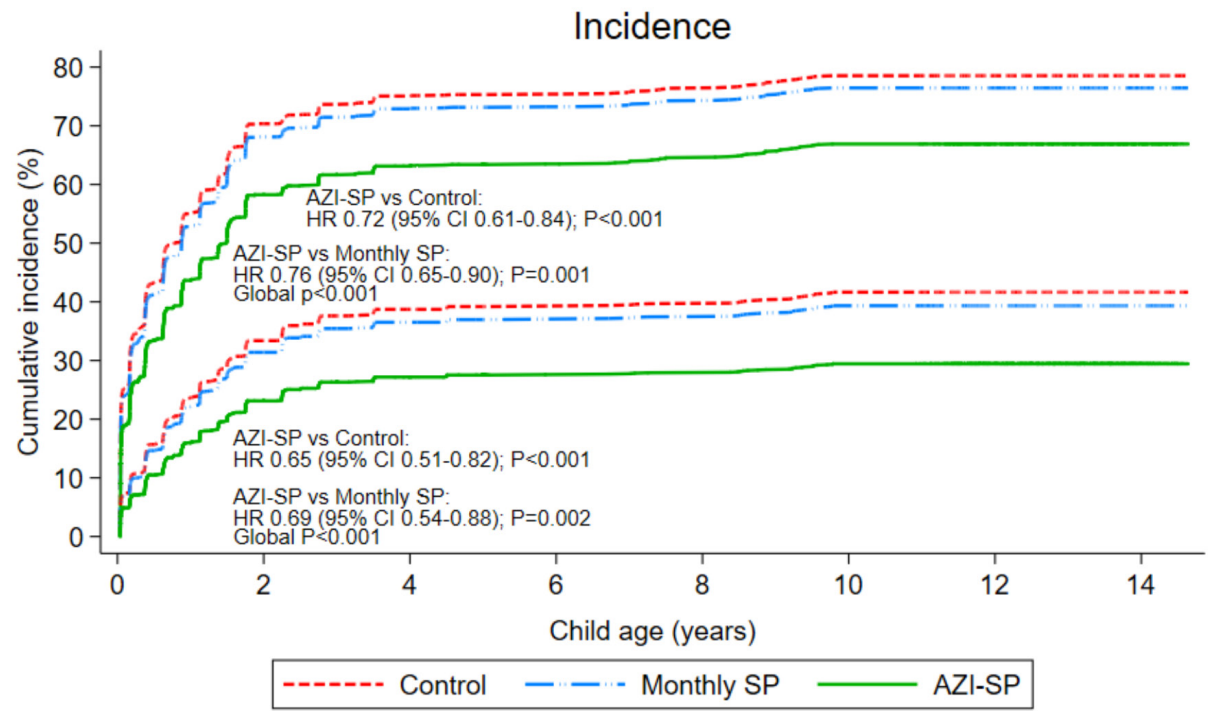

Figure 3 Cumulative incidence of stunting ( $\mathrm{HAZ}<-2 \mathrm{SD})$ and severe stunting (HAZ <-3SD) from 1 month to approximately 13 years of age by intervention group. Stunting ( $\mathrm{HAZ}<-2$, upper sets of lines) and severe stunting ( $\mathrm{HAZ}<-3$, lower sets of lines) are shown. Figure created by the authors. AZI-SP, intervention group with monthly SP and two doses of azithromycin; HAZ, height-for-age Z-score; SP, sulfadoxine-pyrimethamine.

timing of treatment and antibiotic sub-type were different in our trial, but both studies suggest that any impact of maternal antenatal macrolide treatment on child development would have waned by preadolescence.

The most common approach tried to increase birth size is maternal dietary supplementation. Several interventions have been shown to have a positive impact on infant weight and in some studies on length at birth, especially among babies of malnourished women. ${ }^{30}$ However, only a few studies have assessed the persistence of gains in birth size through childhood. In the multicountry Women First trial, babies born to women who had been given lipid-based nutrient supplements during pregnancy were on average $3-4 \mathrm{~mm}$ taller and $60 \mathrm{~g}$ heavier than babies born to women who received no supplement, and the difference persisted for at least 6 months. ${ }^{31}$ Similarly, antenatal dietary supplementation resulted in linear growth benefits reflected in lower stunting prevalence until 5 years of age in two Asian studies. ${ }^{32} 33$ Our results suggest that maternal antenatal infection control during pregnancy could also support healthy growth in the offspring.

In contrast to intrauterine gains in weight-for-length, which are often lost postnatally, ${ }^{7-9}$ intrauterine gains in length seem to be more sustainable. Weight-for-length follows the child's postnatal nutritional status, whereas accrued bone length will not be reduced even in subsequent adverse growth conditions. Intergroup differences in newborn length can, however, disappear if the taller group has a higher mean gestational age at birth because postnatal length gain velocity is inversely associated with duration of pregnancy. ${ }^{7}$ The statistical significance of a given absolute difference in length will also wane over time due to the increasing population variance in length. ${ }^{34}$

Fetal length gain is regulated by insulin-like growth factors (IGFs), secreted by maternal tissues, the placenta and the fetus on various stimuli. ${ }^{35}$ Systemic inflammation, elicited by maternal or placental infection, downregulates the expression of IGFs and their cellular receptors, reduces placental nutrient transfer, and thus causes FGR. ${ }^{36}$ The antenatal intervention of repeated doses of SP and AZI probably promoted fetal growth by reducing systemic inflammation caused by maternal malaria and other infections. ${ }^{11}$ Alleviation of inflammation-induced hypomyelination of fetal brain, leading to better neural connectivity, is a possible mechanism of how the intervention had a positive impact on early child development. ${ }^{14} 1537$ The impact may have subsequently waned because by mid-childhood cognitive development is greatly affected by external factors such as schooling, play sessions and other stimulation. Beyond the first 1000 days, neurocognitive development is a result of early childhood and mid-childhood exposures: disease prevention, nutrition, security and safety, caregiving practices, and early learning possibilities. 4163839

One limitation of our study is the method used for assessing cognitive development. At 5 years of age, we used the Griffith's Mental Developmental Scales, which provides a score for five different developmental domains. With this test, better developmental performance in the AZI-SP group was mainly observed in the 'performance' domain, measuring visuospatial skills such as speed of work and precision. ${ }^{40}$ There is no universally approved instrument for measuring cognitive function among preadolescents in low-income settings. ${ }^{41}$ We used CPM, which is viewed as a culturally robust tool for measuring logical reasoning. ${ }^{19} 2142$ The Raven's test resembles the 'performance' domain in the Griffith's test. The normal distribution of Raven's scores in our sample is reassuring that the test captured appropriately one dimension of child development. However, the mean score was lower than earlier reported from similar-aged children in highincome settings. ${ }^{19}$ Given this caveat and the complexity of child development, ${ }^{1639}$ it is possible that we might have missed a subtle intervention impact on one or more developmental domains.

In conclusion, these findings do not support the hypothesis of long-lasting positive effects of antenatally administered intensive infection control on neurocognitive development. However, the intervention seems to decrease the cumulative incidence of ever being stunted in childhood.

Acknowledgements We thank the study participants and the study staff. Azithromycin and its placebo were provided free of charge by Pfizer (New York, New 
York). SP tablets were obtained from companies with Good Manufacturing Practice certification and quality assurance.

Contributors Conceptualisation: UA, PA. Data curation: $\mathrm{KV}, \mathrm{OH}$. Formal analysis: $\mathrm{OH}$. Funding acquisition: UA, PA. Investigation: UA, CM. Methodology: UA, CM, PA. Project administration: UA, CM. Supervision: UA, PA.

Funding This study was funded by a personal grant from the Foundation for Pediatric Research in Finland. The original LAIS study was supported by grants from the Academy of Finland (grants 79787 and 207010), the Foundation for Pediatric Research in Finland and the Medical Research Fund of Tampere University Hospital.

Competing interests KV: grant from the Foundation for Pediatric Research during the conduct of the study.

Patient consent for publication Not required.

Ethics approval The study was approved by the College of Medicine Research and Ethics Committee (COMREC), Malawi (P.09/17/2280): Adolescents in rural Malawi: growth, development and food habits, version 1, 22 August 2017 by UA; and the Pirkanmaa Health Care District Federation of Municipalities Ethical Committee, Finland (R02166M)

Provenance and peer review Not commissioned; externally peer reviewed. Data availability statement Data are available upon reasonable request. Supplemental material This content has been supplied by the author(s). It has not been vetted by BMJ Publishing Group Limited (BMJ) and may not have been peer-reviewed. Any opinions or recommendations discussed are solely those of the author(s) and are not endorsed by BMJ. BMJ disclaims all liability and responsibility arising from any reliance placed on the content. Where the content includes any translated material, BMJ does not warrant the accuracy and reliability of the translations (including but not limited to local regulations, clinical guidelines, terminology, drug names and drug dosages), and is not responsible for any error and/or omissions arising from translation and adaptation or otherwise.

Open access This is an open access article distributed in accordance with the Creative Commons Attribution Non Commercial (CC BY-NC 4.0) license, which permits others to distribute, remix, adapt, build upon this work non-commercially, and license their derivative works on different terms, provided the original work is properly cited, appropriate credit is given, any changes made indicated, and the use is non-commercial. See: http://creativecommons.org/licenses/by-nc/4.0/.

\section{ORCID iD}

Karoliina Videman http://orcid.org/0000-0002-8367-4451

\section{REFERENCES}

1 Unicef/ WHO/The World Bank. Levels and trends in child malnutrition 47 million 38 million, 2020.

2 Sudfeld CR, McCoy DC, Danaei G, et al. Linear growth and child development in lowand middle-income countries: a meta-analysis. Pediatrics 2015;135:e1266-75.

3 Victora CG, Adair L, Fall C, et al. Maternal and child undernutrition: consequences for adult health and human capital. Lancet 2008;371:340-57.

4 Stiles J. Brain development and the nature versus nurture debate. In: Progress in Brain Research, 2011.

5 Robertson RC, Manges AR, Finlay BB, et al. The Human Microbiome and Child Growth - First 1000 Days and Beyond. Trends Microbiol 2019;27:131-47.

6 Christian P, Lee SE, Donahue Angel M, et al. Risk of childhood undernutrition related to small-for-gestational age and preterm birth in low- and middle-income countries. Int J Epidemiol 2013;42:1340-55.

7 Lanou H, Huybregts L, Roberfroid D, et al. Prenatal nutrient supplementation and postnatal growth in a developing nation: an RCT. Pediatrics 2014;133:e1001-8.

8 Lassi ZS, Padhani ZA, Rabbani A, Rind Amna; , et al. Impact of dietary interventions during pregnancy on maternal, neonatal, and child outcomes in low- and middleincome countries. Nutrients 2020;12. doi:10.3390/nu12020531. [Epub ahead of print: 19 Feb 2020].

9 Ashorn P, Alho L, Ashorn U, et al. Supplementation of maternal diets during pregnancy and for 6 months postpartum and infant diets Thereafter with Small-Quantity lipidbased nutrient supplements does not promote child growth by 18 months of age in rural Malawi: a randomized controlled trial. J Nutr 2015;145:1345-53.

10 Kayentao K, Garner P, Maria van Eijk A, Van Eijk AM, et al. Intermittent preventive therapy for malaria during pregnancy using 2 vs 3 or more doses of SulfadoxinePyrimethamine and risk of low birth weight in Africa. JAMA 2013;309:594-604.

11 Luntamo M, Kulmala T, Cheung YB, et al. The effect of antenatal monthly sulphadoxine-pyrimethamine, alone or with azithromycin, on foetal and neonatal growth faltering in Malawi: a randomised controlled trial. Trop Med Int Health 2013;18:386-97.

12 Unger HW, Ome-Kaius M, Wangnapi RA, et al. Sulphadoxine-Pyrimethamine plus azithromycin for the prevention of low birthweight in Papua New Guinea: a randomised controlled trial. BMC Med 2015;13:9.
13 van den Heuvel M. Metabolomics, stunting and neurodevelopment. EBioMedicine 2019:44:10-11.

14 Hallamaa L, Cheung YB, Maleta K, et al. Child health outcomes after presumptive infection treatment in pregnant women: a randomized trial. Pediatrics 2018;141:e20172459.

15 Hallamaa L, Cheung YB, Luntamo M, et al. The impact of maternal antenatal treatment with two doses of azithromycin and monthly sulphadoxine-pyrimethamine on child weight, mid-upper arm circumference and head circumference: a randomized controlled trial. PLoS One 2019;14:e0216536.

16 Black MM, Walker SP, Fernald LCH, et al. Early childhood development coming of age: science through the life course. Lancet 2017;389:77-90.

17 Luntamo M, Kulmala T, Mbewe B, et al. Effect of repeated treatment of pregnant women with sulfadoxine-pyrimethamine and azithromycin on preterm delivery in Malawi: a randomized controlled trial. Am J Trop Med Hyg 2010;83:1212-20.

18 Raven J, Raven J, C; Court J. Manual for Raven's Progressive Matrices and Vocabulary Scales. Section 2: Coloured Progressive Matrices. 1998 Editi, 1998.

19 Cotton SM, Kiely PM, Crewther DP, et al. A normative and reliability study for the Raven's Coloured Progressive Matrices for primary school aged children from Victoria, Australia. Pers Individ Dif 2005;39:647-59.

20 Wicherts JM, Dolan CV, Carlson JS, et al. Raven's test performance of sub-Saharan Africans: Average performance, psychometric properties, and the Flynn Effect. Learn Individ Differ 2010;20:135-51

21 Teivaanmäki T, Bun Cheung Y, Pulakka A, et al. Height gain after two-years-of-age is associated with better cognitive capacity, measured with Raven's coloured matrices at 15-years-of-age in Malawi. Matern Child Nutr 2017;13:e12326-12.

22 de Onis M, Onyango AW, Borghi E, et al. Development of a who growth reference for school-aged children and adolescents. Bull World Health Organ 2007;85:660-7.

23 WHO Multicentre Growth Reference Study Group. Who child growth standards based on length/height, weight and age. Acta Paediatr Supp/ 2006;450:76-85.

24 Marshall WA, Tanner JM. Growth and physiological development during adolescence. Annu Rev Med 1968;19:283-300.

25 McNamee R. Regression modelling and other methods to control confounding. Occup Environ Med 2005:62:500-6.

26 Cheung YB. Statistical Analysis of Human Growth and Development. Chapman \& Hall/ CRC Biostatistics Series, 2014.

27 Kenyon S, Taylor DJ, Tarnow-Mordi WO. ORACLE - Antibiotics for preterm prelabour rupture of the membranes: Short-term and long-term outcomes. In: Acta Paediatrica, International Journal of Paediatrics, Supplement, 2001: 12-15.

28 Kenyon S, Pike K, Jones DR, et al. Childhood outcomes after prescription of antibiotics to pregnant women with spontaneous preterm labour: 7-year follow-up of the ORACLE II trial. Lancet 2008;372:1319-27.

29 Marlow N, Bower H, Jones D. The ORACLE children study: educational outcomes at 11 â $€$.years of age following antenatal prescription of erythromycin or co-amoxiclav. Arch Dis Child Fetal Neonatal Ed 2017.

30 Dewey KG. Reducing stunting by improving maternal, infant and young child nutrition in regions such as South Asia: evidence, challenges and opportunities. Matern Child Nutr 2016;12 Suppl 1:27-38.

31 Krebs NF, Hambidge KM, Westcott JL, et al. Growth from Birth Through Six Months for Infants of Mothers in the "Women First" Preconception Maternal Nutrition Trial. J Pediatr 2021;229:199-206.

32 Kusin JA, Kardjati S, Houtkooper JM, et al. Energy supplementation during pregnancy and postnatal growth. Lancet 1992;340:623-6.

33 Khan Al, Kabir I, Ekström E-C, et al. Effects of prenatal food and micronutrient supplementation on child growth from birth to 54 months of age: a randomized trial in Bangladesh. Nutr J 2011;10:134

34 Lundeen EA, Stein AD, Adair LS, et al. Height-for-age Z scores increase despite increasing height deficits among children in 5 developing countries. Am J Clin Nutr 2014; 100:821-5

35 Woods KA, Camacho-Hübner C, Savage MO, et al. Intrauterine growth retardation and postnatal growth failure associated with deletion of the insulin-like growth factor I gene. N Engl J Med 1996;335:1363-7.

36 Dimasuay KG, Boeuf $P$, Powell TL, et al. Placental responses to changes in the maternal environment determine fetal growth. Front Physiol 2016;7:12.

37 Suchdev PS, Boivin MJ, Forsyth BW, et al. Assessment of neurodevelopment, nutrition, and inflammation from fetal life to adolescence in low-resource settings. Pediatrics 2017; 139:S23-37.

38 Prendergast AJ, Humphrey JH. Paediatrics and international child health the stunting syndrome in developing countries the stunting syndrome in developing countries. Paediatr Int Child Health 2014;34:250-65.

39 Grantham-Mcgregor S, Smith JA. Extending the Jamaican early childhood development intervention. J App/ Res Child 2016;7.

40 Griffith R. Luiz dA for research in infant and child development. Griffiths mental development scales, extended revised: GMDS-ER; two to eight years, 2006

41 Richter L, Mabaso M, Hsiao C. Predictive power of psychometric assessments to identify young learners in need of early intervention: data from the birth to twenty plus cohort, South Africa. S Afr J Psychol 2016;46:175-90.

42 Raven J. The raven's progressive matrices: change and stability over culture and time. Cogn Psychol 2000;41:1-48 